\title{
Determinant factors of partisans' confirmation bias in social media
}

\author{
Rahkman Ardi, Adismara Putri Pradiri \\ Faculty of Psychology, Universitas Airlangga, Indonesia \\ Corresponding author: rahkman.ardi@psikologi.unair.ac.id
}

\section{ARTICLE INFO}

Article history

Received January 20, 2021

Revised February 15, 2021

Accepted February 20, 2021

Keywords

authoritarian personality;

critical openness;

collective entitlement;

political preference;

reflective skepticism.

\begin{abstract}
Partisans are more likely to be motivated by a desire to justify their political opinion which is called as confirmation bias. This research aimed to investigate the determinant factors of confirmation bias among college students who actively obtained political information in social media. All participants were associated with a student organization of particular political ideologies. The determinant factors of confirmation bias under investigation were critical thinking, consisting of two dimensions-i.e., critical openness and reflective skepticism; authoritarian personality; collective entitlement; and political preference. A confirmation bias scale pertaining to media reporting was specifically constructed for the purpose of this study. The measurement of critical thinking, authoritarian personality, and collective entitlement utilized existing instruments. The sample in this study was 95 students with various political ideologies. Hierarchical multiple regression analysis was conducted to analyze the data. The current study results demonstrated that critical openness, collective entitlement, and authoritarian personality were predictors of confirmation bias. Meanwhile, reflective skepticism and political preference were not significant predictors. The findings could be the building blocks for developing an intervention to increase digital citizenship awareness by open-mindedness to reduce confirmation bias among social media users.
\end{abstract}

\section{Introduction}

The existence of the internet and social media may positively impact democracy by providing autonomy for individuals in creating contents and getting limitless information accessible to anyone (Dahlberg, 2007). These recent media have also changed the direction of information no longer based on one-way broadcasts but occurs in various directions and various parties. Agenda setting and propaganda that are usually carried out based on framing of traditional media broadcasting can easily be unmatched by other resources in internet providing different perspectives that can be created by anyone (Ardi, 2021). Internet users and any new media can easily find reinforcement and justification for what they personally believe and disseminate their views in a broader network.

In the research of Shin \& Thorson (2017) and Ardi (2019), partisan internet users were caught several times not doing fact-checking on news that was misleading, provocative and unjustified truth. They selectively only share messages that have fact-checked if the news only supports their candidate and demeans the opposing candidate so that the stream of facts has been selected and narrowed (Shin \& Thorson, 2017). Garrett (2009) states that individuals 
tend to be motivated by a desire to justify their political opinion while using the media. This motivation then leads individuals to have confirmation bias.

Confirmation bias is seen as the tendency to support information that confirms one's initial assumptions and preconceptions rather than to explore the information more scientifically and neutrally (Hogg \& Vaughan, 2011). The investigation of confirmation bias in social media is motivated by the echo chamber phenomenon where social media algorithm directs users to reinforce their existing beliefs. This phenomenon occurs because the priority in search engine results and social media newsfeed is based on the user's activities, such as the history of sharing, clicks, likes, comments, feeds, and searching (Bessi, 2016; Jamieson \& Cappella, 2008; Tufekci, 2015). It is alleged to make the most of the users would be like a frog in a shell when one sees certain events based solely on the contents of media on the internet (Montag, 2019). The Internet has made individuals the central point of information consumption and production. On the other hand, media algorithms have also created these individuals, who tend to be uncritical, close-minded, authoritarian, and who perceive their group as superior to the others, be further trapped in their biased beliefs.

For internet users, critical thinking has a fundamental role as an initial filter to decide whether or not to trust a piece of information before sharing it with more audiences. Several studies reported that hoaxes frequently are shared without further confirmation and reflection of their truth. Snowden (Kutner, 2016) explained that tackling hoaxes' spread improves internet users' critical thinking. Researchers from the French National Institute and Columbia University reported that 59 percent of all links shared in social media were never read by the sharer (Gabielkov et al., 2016). A survey in Indonesia also indicated that the spread of hoaxes was caused by a lack of reflection on the news contents before sharing them (Mastel, 2017). The news was assumed to represent the truth which they and their close relative endorsed. Mastel (2017) found that 47\% of participants admitted sharing phenomenal news because they received them from trusted people. While 32 percent did so because they thought the news was beneficial, 18 percent thought the news was accurate, and the rest three percent shared the news because they wanted to be the first to do so.

Critical thinking is defined as the propensity and skills to engage in activity and mental activity with reflective skepticism focused on deciding what to believe or do (Halonen, 1995). However, critical thinking is related to cognitive issues and closely associated with personal dispositions, namely openness to experience (Clifford, Boufal, \& Kurtz, 2004). Sa, Stanovich, \& West (1999) stated that critical thinking per se is a manifestation of cognitive ability and cognitive decontextualization. Cognitive ability refers to an individual's intellectual capacity, while cognitive decontextualization refers to the flexibility and openness of thinking. Sosu (2013) divided critical thinking into two dispositional capacities: critical openness that tends to be actively open to new ideas and experiences, and reflective skepticism, which is one's tendency to reflect on one experience. Both Sa et al. (1999) and Sosu (2013) indicated two essential aspects of critical thinking, namely internal capacity (e.g., IQ or reflective ability) and decontextualizing ability or the ability to understand the context through openness and new experience.

This conceptualization differs from a definition by Watson \& Glaser (1991), who divide critical thinking into five different dimensions: inference, recognition of assumption, deduction, interpretation, and evaluation. These five dimensions do not incorporate openness in thinking but merely address analytical thinking. There is evidence that such facets of critical thinking bear no association with an individual's ability to avoid bias from selective exposure or confirmation bias (Ardi, 2019). Kenyon \& Beaulac (2014) and Mercier \& Sperber (2011) also state that critical thinking skill is not sufficient for debiasing to happen when the individual has already assumed a particular standing point. On one side, a prior investigation by Ardi (2019) suggested a possible negative association between openmindedness and confirmation bias. Therefore, warrants an exploration of a possible link 
between critical thinking - including its analytical aspect and the open-mindedness aspect of it - and confirmation bias. However, Beyer (1995) asserts that critical thinking should encourage individuals to think in an open-minded, sceptical, and fair-minded manner and appreciate different stand points.

Sa et al. (1999) showed that the individual's critical thinking determines belief bias in seeing reality. It means that if one has critical thinking skills and is also open to different ideas and experiences, they tend to minimize belief bias. Confirmation bias itself indicates how individuals only prefer their own existing beliefs and ignore different perspectives (Hogg \& Vaughan, 2011; Wason, 1960).

Another factor related to confirmation bias, such as authoritarian personality, is of particular interest due to the finding of the previous study by Lavine, Lodge, \& Freitas (2005). Authoritarian personality refers to a high degree of conformity, rigidity, and compliance to authorities, superiors, or particular groups and a tendency to subordinate other groups (Adorno et al., 1950; Hogg \& Vaughan, 2011). It is typical traits of anti-democracy characters (Adorno et al. 1950; Hogg \& Vaughan, 2011). It might be manifested in prejudice against different groups as well as in conservative, dogmatic, and ethnocentric attitudes. Lavine et al. (2005) found that individuals who tend to be authoritarian and whose interests are threatened tend to engage in selective exposure to attitude-congruent information. Therefore, individuals with a high degree of authoritarian personality who at the same time perceive their interest as being threatened, will be more likely to choose news contents which support their belief.

Another hypothesis related to the collective entitlement and confirmation bias was established based on the assumption of how entitled individuals exhibit narcissism and tend to be biased to respond to information. Campbell, et.al (2004) confirms entitlement itself is a component of narcissism. According to Campbell et al. (2004), psychological entitlement refers to a sense of entitlement experienced across situations. Psychological entitlement is an experience in which one feels being deserving and entitled. An essential aspect of psychological entitlement is how the individuals see themselves in a positive light (Harvey \& Martinko, 2008; Snow, Kern, \& Curlette, 2001). In order to maintain their self-image, individuals are often distorted by perceiving reality following their expectancies (Harvey \& Martinko, 2008; Zuckerman, 1979).

In this research, entitlement is not tested on the individual level but instead on the collective scope. Like self-esteem, which is seen as the degree to which individuals evaluate their self-esteem as a consequence of being a part of a particular group (Crocker \& Luhtanen, 1990), the concept of individual entitlement is assumed to be applicable in the collective domain. This refers to how an individual feels that their group deserves and is entitled to something.

Collective narcissism leads to a siege belief system, a mental state in which individuals tend to distrust and have negative attitudes toward other groups (Golec de Zavala \& Cichocka, 2011). Such a mental state leads to a bias in responding to information. A study by Toma, Bry, \& Butera (2013) demonstrated how individuals in competitive settings tend to regard information within their group as superior over those spread among other groups. It means that individuals who are likely to regard themselves as more deserving and entitled and are in a competitive situation tend to experience confirmation bias by selecting information that supports their group.

Furthermore, the relationship between political preference and confirmation bias is based on contextual phenomena. After the 2014 presidential election, Indonesian social media users seemed to be divided into two entities: the pro-elected president and the pro-opposition side (Mietzner, 2015). The pro-president stronghold was associated with progressive nationalists. It was supported by secular nationalistic group and inclusive traditional Islamists. In contrast, the pro-opposition stronghold was associated with the conservative group 
supported by conservative nationalist and right-winged Islamic groups (Mietzner, 2015). Fierce clashes in social media between the two strongholds were continued into the 2017 election of the governor of DKI Jakarta (Lim, 2017). Scorn and hate speeches toward each other were demonstrated both vulgarly and emotionally by both groups in social media. The pro-incumbent president side would show off news from selected media that praised the president and mocked the opposition's weaknesses. Vice versa, the pro-opposition derided the president with negative contents and eulogized the leader of the opposition side by exhibiting positive images. Furthermore, both sides tended to ignore the validity of the information source when praising their political leader and to mock the other leader (Mastel, 2017). The study by Shin \& Thorson (2017) showed that partisans would only tend to choose news that supports their own views. However, there were assumptions from other researchers that supporters of conservative values were more swayed by the negativity bias (Fessler, Pisor, \& Holbrook, 2017) and influenced by stereotypes-disconfirming evidence (Flynn, 2005).

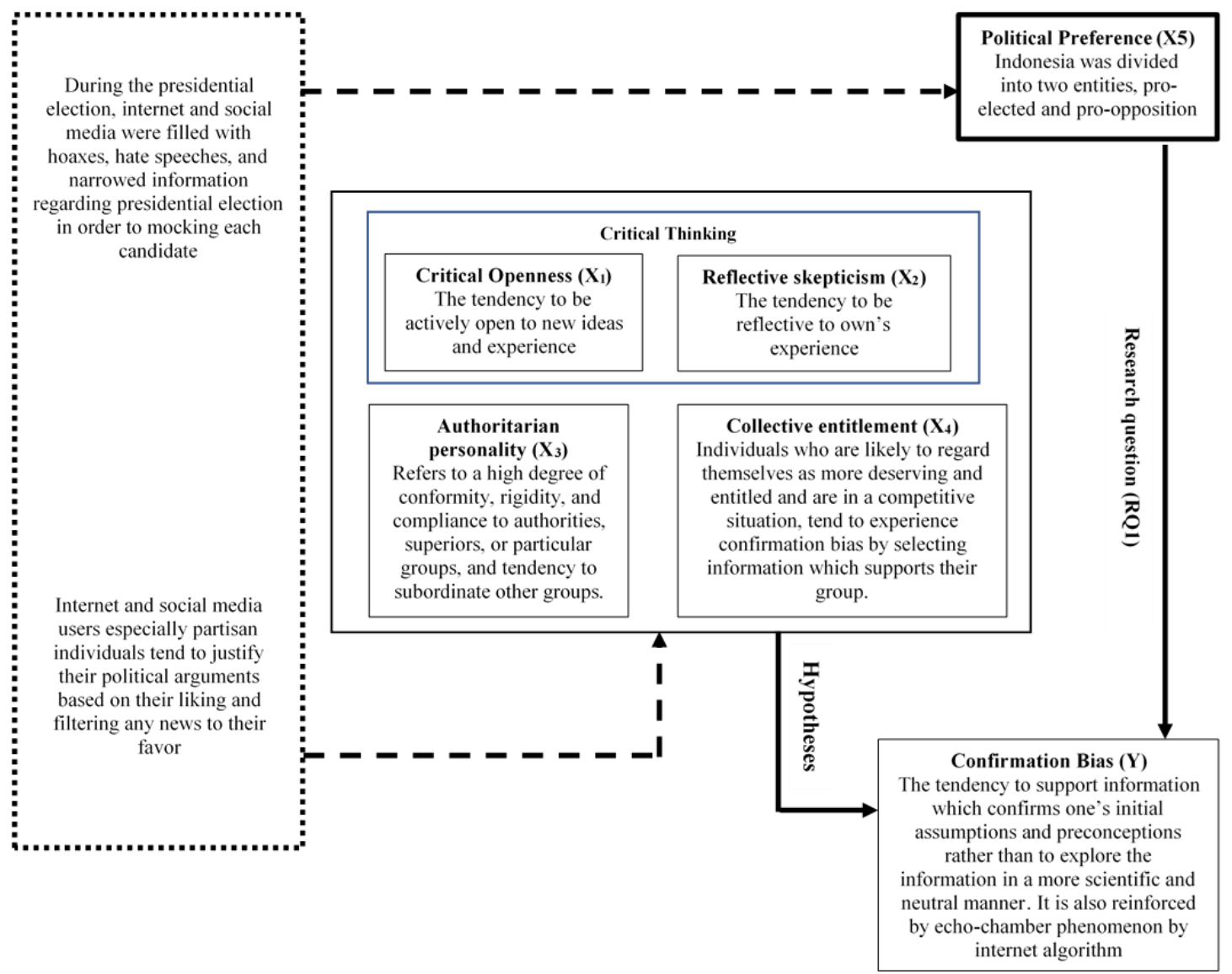

Figure 1. Conceptual framework

Figure 1 depicts the conceptual framework of the study reported in this article. Based on those prepositions, the following research question was formulated: Is there a correlation between political preference manifested in presidential candidates' election and confirmation bias (RQ1)? The following hypotheses were formulated for this study: (H1) Critical openness would negatively predict the tendency for confirmation bias; $(\mathrm{H} 2)$ Reflective skepticism would negatively predict the tendency for confirmation bias; (H3) Authoritarian personality 
would positively predict the tendency for confirmation bias; (H4) Collective entitlement would positively predict the tendency for confirmation bias.

\section{Method \\ Participants}

The researchers obtained a list of participant candidates who actively joined ideologicalnuanced extra-campus organizations in a public university in Surabaya. Extra-campus organizations are student-led organizations with a particular political ideology, whether it's nationalism, inclusive Islam, or conservative Islam, that stresses religious propagation. The surveyor then contacted these candidates to ask for their willingness to participate in the current study. A total of ninety-five (95) participants took part in this research. All participants were a member of an ideological-nuanced extra-campus organization affiliated with a community organization or political party.

Initial sample planning was calculated with a priori power analysis using $\mathrm{G}^{*}$ Power software (Faul, Erdfelder, Buchner, \& Lang, 2009). The study by Lavine et al. (2005) showed that predictors of authoritarian personality explained nine percent variation in selective exposure $\left(f^{2}=.098\right)$. The effect size of their study was used as a baseline for the regression model built on the current study, thereby by a priori power analysis, we obtained a minimum sample size of $136\left(f^{2}=.098\right.$, power statistic .80 , alpha .05 , and 5 predictors $)$. This study only had 95 participants because low enthusiasm and willingness to participate. Furthermore, sensitivity power analysis was conducted $(\alpha=.05$, power .8 , sample size 95 , number of predictors $=5$ ) and obtained the smallest effect size $f^{2}=.14$ that the study could have detected. The effect size obtained from the sensitivity analysis was larger than the study conducted by Lavine et al. (2005), but it was considered as reasonable especially given the fact that the characteristic of participants in current study was more specific. Participants in the study of Lavine et al. (2005) only involved university students in general, however this study concerned to students joining organizations with political ideology.

The participants were students of bachelor's programs in a public university in Surabaya, Indonesia, aging from 18 to 24 -year-old $(M=20.51 ; S D=1.24)$. The gender proportion was $59 \%$ males and $41 \%$ females. A total of $44 \%$ of the participants reported spending time online more than four hours a day, 24\% spared three to four hours a day, $19 \%$ spent two to three hours a day, while the rest spared less than two hours a day. Sixty-one percent reported religious nationalism as their preferred ideology, 14\% preferred nationalism, $7 \%$ wanted a religious law-based nation, $11 \%$ identified as a democrat-socialist. In comparison, the remaining $7 \%$ had other political preferences. A total of $37 \%$ of the students were for Jokowi (the incumbent president, $46 \%$ were pro-Prabowo (the opposition), while the rest abstained.

\section{Procedures}

The data was collected in November 2017 (i.e., one year prior to the 2019 presidential election). The questionnaire was delivered paper-based. During the completion of the questionnaire, participants were assisted by a surveyor.

The participants' recruitment was carried out purposively by providing a form of consent to participate in the research. The form stated that the research concerned the profile and activities of social media users who actively obtained political news information on their social media page. 


\section{Instruments}

Instruments in this research included the confirmation bias scale, the authoritarian personality scale, the critical thinking disposition scale, and the collective entitlement scale. In this case, participants responded to each item on a scale from 1 (strongly disagree) to 7 (strongly agree). Demographic data such as age, gender, frequency of internet use was also analyzed in this study. Political preference was obtained by asking the participant's preference in the 2014 presidential election. The questionnaire was coded with the following order: 0 for those who didn't vote, 1 for voting for the elected president, and 2 for those who voted for the opposition. During the analysis, political preference was treated as a dummy variable. Thus, the coding would only be based on two groups, namely, the opposition coded as 1 and 0 for preferences other than the opposition side.

The confirmation bias scale was constructed for this study and consisted of five items. Item construction was based on the definition of confirmation bias from Hogg \& Vaughan (2011) and the literature reviews conducted by Cappella, Kim, \& Albarracin (2015), which state that there are motives to defend attitudes, beliefs, and behaviors when a person consumes media. A KMO score of .76 in this variable and the result of the Bartlett test of sphericity $\left(\chi^{2}\right.$ $(10)=228.52(\mathrm{p}<.05))$ indicated that the sample was adequate to meet the requirements for a factor analysis. An exploratory analysis using maximum likelihood method with varimax orthogonal rotation (based on eigenvalues greater than one) resulted in one factor structure (Eigenvalue $=3.11$; factor loadings $=.60-.86$ ), which explained $62.26 \%$ of the total variance. In other words, this scale was a unidimensional measure. The internal reliability of this scale was good $(\alpha=.84 ; 5$ items). The items, along with their factor loading, can be located in Table 1.

Table 1

Factor Loading of Items in The Confirmation Bias Scale

\begin{tabular}{clc}
\hline No. & \multicolumn{1}{c}{ Item } & $\begin{array}{c}\text { Factor } \\
\text { loading }\end{array}$ \\
\hline 1 & I only want to read news sources that support what I already believe. & .86 \\
2 & I ignore news contents that criticize what I believe. & .79 \\
3 & I look for information that can justify what I believe. & .60 \\
4 & I interpret a particular piece of information to support what I believe. & .62 \\
5 & Information that conflicts with my belief is merely contrived information. & .69 \\
\hline
\end{tabular}

Critical thinking in the current study was measured using the critical thinking disposition scale (Sosu, 2013). This scale was adopted through forwarding translation from English to Indonesian without any adaptation process. There are two dimensions of critical thinking disposition assessed in this scale. First critical openness with reliability $\alpha=.671$; and consists of four items; e.g., "I use more than one source to find out information for myself." Second reflective skepticism with reliability $\alpha=.70$; and consists of three items; e.g., "I often re-evaluate my experiences so that I can learn from them."

Authoritarian personality was measured by the modified F scale developed by Anesi (1997) from the authoritarian personality theory (Adorno et al. 1950; Hogg \& Vaughan, 2011). The scale was then forwarded translation from English to Indonesian without any adaptation process. Two expert judgments rated the appropriateness of the items with an Indonesian background. Through this process, only 17 items were deemed appropriate. Some more items were eliminated further to improve the Cronbach's alpha reliability coefficient (Nunnally, 1978), leaving only 12 items (e.g. "obedience and respect for authority are the most important virtues children should learn") in the modified version with $\alpha=.74$. 
Collective entitlement is an individual's tendency to perceive their group as being deserving and entitled. It was assessed using the collective entitlement scale adopted and modified from the psychological entitlement scale (Campbell et al., 2004). This scale was forwarded translation of the original English version into Indonesian. The modification in this scale was made by replacing "I" with "Our group," e.g., "We honestly feel our group just more deserving than others." The scale consists of seven items, with reliability $\alpha=.86$.

\section{Data analysis}

The assumption test was carried out, and the result showed no multicollinearity where the VIF between predictors in each model ranged from 1.00 to 1.24. Also, the residual was normally distributed, and heteroscedasticity did not occur. There was no autocorrelation with the Durbin-Watson value $=1.73$. Cook's distance test also showed no substantial effect of one case/outlier, affecting the regression coefficient. A correlational analysis was carried out among the variables. A hierarchical multiple regression analysis was proceeded to evaluate a model and test the hypotheses.

\section{Results}

All participants used social media to get political information. However, sixty percent of them had also been actively involved in discussions and comments about Indonesian political dynamics on social media. While 28.4 percent were rarely and very rarely involved in such online discussions, and the remaining 11.6 percent preferred not to say. The majority of participants reported that they most often discussed political issues on their friend's social media wall $(43.1 \%)$, followed by on a public figure's fan page $(25.3 \%)$ and a mass media's fan page $(25.3 \%)$. In comparison, $6.3 \%$ of participants did not answer.

Data on confirmation bias was categorized based on a hypothetical norm. Confirmation bias scores were group into three categories: low ( $x \leq 2.63)$, moderate $(2.63<\mathrm{x} \leq 4.36)$, dan high $(x>4.36)$. Based on this grouping, 36 participants were identified with a high tendency for confirmation bias, and the other 43 participants were in the moderate group. In comparison, the remaining 16 participants were categorized as having a low level of confirmation bias tendency.

The result of Pearson's correlational analysis showed that authoritarian personality, critical openness, and collective entitlement were correlated with confirmation bias (see Table 2). However, reflective skepticism and political preference to the opposition were not correlated with confirmation bias. Additionally, significant correlations were found between other variables as formalized in the hypotheses. Based on the findings from hierarchical multiple regression analysis, it was concluded that $\mathrm{H} 2$ was not supported. Regarding RQ1, it can be concluded that there is no significant correlation between political preferences with confirmation bias.

Table 2

Correlation between Observed Variables

\begin{tabular}{ccccccccc}
\hline & $M$ & $S D$ & 1 & 2 & 3 & 4 & 5 & 6 \\
\hline Confirmation Bias (1) & 3.84 & 1.28 & 1 & & & & & \\
Critical Openness (2) & 5.83 & .72 & $-.21^{*}$ & 1 & & & \\
Reflective Skepticism (3) & 6.08 & .71 & .05 & $.38^{* *}$ & 1 & & \\
Authoritarian (4) & 4.78 & .78 & $.35^{* *}$ & .14 & .20 & 1 & & \\
Collective Entitlement (5) & 3.98 & 1.15 & $.34^{* *}$ & .09 & .12 & $.43^{* *}$ & 1 & \\
Political Preference (6) & .45 & .50 & .06 & .02 & .05 & .20 & .13 & 1 \\
\hline
\end{tabular}

**. Significant on .01 level (2-tailed). *. Significant on .05 level (2-tailed) 
Table 3 shows the hierarchical multiple regression yielded that at stage one, critical openness contributed significantly to the regression model, $F(1.93)=4.65, p<.05, R^{2}=.048$, effect size $f^{2}=.05$ ). Introducing the authoritarian personality tendency explained an additional $15.2 \%$ variation in confirmation bias, and this change in $R^{2}$ was significant (effect size $f^{2}=.17$ ), $F(1,92)=17.47, p<.01$. Adding collective entitlement to the regression model explained an additional $5 \%$ of the variation in confirmation bias and this change in $R^{2}$ was significant (effect size $\left.f^{2}=.05\right), F(1.91)=6.04, p<.05$. The most important predictor of confirmation bias was authoritarian personality, which uniquely explained $15.2 \%$ of confirmation bias variation. Together the three independent variables accounted for $25 \%$ of the variance in confirmation bias (effect size $f^{2}=.33$ ).

The third model revealed that participants with low critical openness would have a high tendency for confirmation bias $[B=-.50,95 \% C I[-.82,-.17], t(91)=-3.06, p=.003)]$. Likewise, participants who had the tendency for authoritarian personality $B=.47,95 \% C I$ $[.14, .80], t(91)=2.83, p=.006)$ and collective entitlement $[B=.27,95 \% C I[.05, .49], t(91)$ $=.24, p=.016$ )] would also show high levels of confirmation bias. Based on these findings, it was concluded that $\mathrm{H} 1, \mathrm{H} 3$, and $\mathrm{H} 4$ were supported.

Table 3

Hierarchical Regression Analysis of Determinant Variables

\begin{tabular}{|c|c|c|c|}
\hline & Model 1 & Model 2 & Model 3 \\
\hline \multicolumn{4}{|c|}{ Critical openness } \\
\hline$B$ & $-.38 *$ & $-.48 * *$ & $-.50 * *$ \\
\hline$S E B$ & .18 & .16 & .16 \\
\hline$B 95 \% C I$ & $-.74,-.03$ & $-.81,-.15$ & $-.82,-.17$ \\
\hline$\beta$ & $-.21 *$ & $-.27 * *$ & $-.28 * *$ \\
\hline \multicolumn{4}{|c|}{ Authoritarian personality } \\
\hline$B$ & & $.64 * *$ & $.47 * *$ \\
\hline$S E B$ & & .15 & .16 \\
\hline$B 95 \% C I$ & & $.33, .95$ & $.14, .80$ \\
\hline$\beta$ & & $.39 * *$ & $.28^{* *}$ \\
\hline \multicolumn{4}{|c|}{ Collective entitlement } \\
\hline B & & & $.27 *$ \\
\hline$S E B$ & & & .11 \\
\hline$B 95 \% C I$ & & & $.05, .49$ \\
\hline$\beta$ & & & $.24 *$ \\
\hline$R^{2}$ & .048 & .20 & .25 \\
\hline$R^{2}$ change & $.048^{*}$ & $.152 * *$ & $.05 *$ \\
\hline
\end{tabular}

**. Significant on .01 level (2-tailed). *. Significant on .05 level (2-tailed)

\section{Discussion}

The descriptive analysis showed that $60 \%$ of participants were actively involved in the comment sections concerning Indonesian political issues on social media. The majority of participants also reported discussion and commenting on a friend's social media wall, in the comment section of a mass media's and public figure's or politician's fan page. Peacock \& Leavitt (2016) explain that youths who are active on social media tend to get involved in political information exchange with three different types of people: 1) close others; 2) informed others; and 3) flexible, moderate, and calm individual. The first type refers to those who are known throughout one's daily life. Relations with these people evoke comfort and are based on trust and respect compared to when a young individual discusses political issues with acquaintances or strangers. In addition, close others are unlikely to show dominance in discussions and debates. The second type includes those who are regarded as credible, welleducated, and trustable. Meanwhile, the third type refers to how youths prefer to discuss 
flexibly, moderate, and calmly without being overly passionate or overly emotional. Peacock \& Leavitt (2016) also show how social media users tend to avoid discussion with extreme partisanship people.

Participants in this study were partisans who participated in a student organization with a particular political ideology. The finding of the current study, along with the elaboration by Peacock \& Leavitt (2016), provides an idea of why the majority of participants were more comfortable discussing political issues with their friends. Such a preference might indicate that individuals tend to avoid ambiguous and unpredictable situations. The political reality is not a single reality but is a multi-interpretation. The multi-interpretation nature of political reality causes ambiguity. Familiar individuals are more likely to be perceived as more readily predictable. Hence it minimizes ambiguity and solves subjective uncertainty (Hogg \& Vaughan, 2011). The finding could also indicate confirmation bias symptoms where individuals only chose familiar friends because the chance of getting approval was more extensive compared to discussions with strangers on social media. Regardless of the descriptive data, 37.8 percent of participants had a high tendency for confirmation bias, and 45.2 percent were identified with moderate tendency. However, it was impossible to determine whether or not discussion with friends had a significant role in confirmation bias without knowing the content and the dynamics of the discussions.

The results indicating that critical openness, authoritarian personality, and collective entitlement were significantly associated with confirmation bias confirmed some of the hypotheses. The negative association between critical openness and confirmation bias demonstrated that an individual who was open to different perspectives and experiences would have a low tendency for confirmation bias. This finding supported Ardi (2019), who suggested the importance of investigating the link between open-mindedness and confirmation bias. It also supported an assumption by Wade (1995) that one of the functions of critical thinking is to take into account alternative interpretations and analyze assumptions and biases. This implies that individuals who dare to explore new ideas and experiences will be isolated and trapped in confirmation bias.

However, reflective skepticism was not found to correlate with confirmation bias. Despite being a critical thinking dimension, reflective skepticism differs from critical openness (Sosu, 2013). Reflective skepticism concerns how individuals introspect by looking back at their past, while critical openness is more about openness to new ideas and information (Sosu, 2013). It means that reflective skepticism is more internally oriented, while critical openness is about exploring information beyond oneself. This finding is in line with Shadrikov (2013) statement that reflection is characterized in general by its orientation to our inner world. It is experienced with various manifestations such as emotional states and feelings, shame, and acts of consciousness (Shadrikov, 2013). Based on this explanation, individuals who have the tendency for reflective skepticism can reflect on truths merely based on themselves as the reference or they can also reflect on their experience by comparing it with others, but its orientation is still inward without openness to new experiences. These two strategies for reflection are assumed to underlie the non-significant correlation between reflective skepticism and confirmation bias.

Further, the current study results also demonstrated that if an individual was compliant to authority and regarded their group as superior over others, they tended to believe in the truth endorsed by their own group. This result confirmed a previous study by Lavine et al. (2005), which revealed the association between tendency for authoritarian personality and confirmation bias. A similar finding was also reported by a meta-analysis by Hart et al. (2009) in which close-mindedness, characterized by a high tendency for authoritarianism among others, was positively correlated with congeniality bias.

Likewise, people who perceived their group as more deserving and entitled (i.e., collectively entitled) would ignore the truths outside their group, meaning that they assumed 
the ingroup's pre-existing belief as to the main source of truth. Entitlement is a component of narcissism (Campbell et al., 2004) and may cause an individual to experience a biased perception of intergroup reality (Golec de Zavala, Dyduch-Hazar, \& Lantos, 2019). It is because individuals who perceive their group as superior and entitled to anything will feel that each of their opinions has been confirmed by their ingroup and are willing to distort the perception of observable facts to protect their ingroup's claim to exceptionality (Golec de Zavala et al., 2019).

However, this study shows the non-significant association between political preferences - which is represented based on whether the participants choose an opposition or not- with a confirmation bias. It can be explained by a study by Brandt, et al. (2014), which reported that liberals and conservatives tend to express the same level of intolerance against different ideologies and threatening groups. It means that individuals can still be trapped with their pre-assumption regardless of their political preference. There is a tendency for falseconsensus bias where individuals regard their values and behaviors as typical and normal for other people in the same situation (Hogg \& Vaughan, 2011). A study by Sokolosi, Markowitz, \& Bidwell (2018) showed that pluralistic ignorance effect and false consensus effect were more likely to happen among groups supporting or opposing a particular issue. However, everyone is very likely to lack access to others' cognition, so one tends to justify what their group believes, regardless of their ideological background. Sokolosi et al. (2018) stated that the root of pluralistic ignorance and false consensus bias was a disparity "between the true normative opinion in a group or population (i.e., what the majority of people actually do believe) and what individuals perceive the norm to be (i.e., what an individual believes others think. The tendency to perceive a consistent worldview can lead someone to find it hard to accept differences from outgroup, hence they keep using their preexisting belief in seeing the world.

One limitation of this research was the absence of questions about the content of discussions and comments posted. It is necessary to determine whether the discussions and comments contained debates on particular political beliefs or are rather about seeking support for their belief. By knowing the comments' content, the behavioral manifestation of confirmation bias in more distant relations and with people from different ideologies will be more vivid.

Another limitation of this study was that it did not examine the external aspects causing individuals to have confirmation bias, such as whether the participants' social media newsfeed actually covered news congruent with their values. This research also used self-rating scales, which have their weaknesses. The observation of confirmation bias is possible by observing the consistency between the endorsed political ideology with the contents that the participants follow and share in social media. Additionally, suspicion towards and resistance against research were also indicated. For example, some participants thought that the research project had a hidden political agenda. Although it was understandable given the political situation at the time, this issue prevented the project from recruiting more participants. Future studies are expected to accommodate these limitations.

\section{Conclusion}

The results of the current study imply that reducing confirmation bias requires flexibility and open-mindedness. The results also confirm that blind obedience and excessive feelings of entitlement increase confirmation bias. It indicates that the ability to be open-minded is necessary because blind obedience to authority and excessive entitlement can only be questioned critically through open-minded thinking. Considering how important authoritarian personality is as a predictor of confirmation bias, it is recommended in further studies to 
investigate the role of authoritarian personality as a mediator variable. The findings could be the building blocks for developing an intervention to increase digital citizenship awareness by open-mindedness to reduce confirmation bias among social media users.

\section{References}

Adorno, T. W., Frenkel-Brunswik, E., Levinson, D. J., \& Sanford, R. N. (1950). The authoritarian personality. Harper and Row.

Anesi, F. (1997). The F Scale. Retrieved March 1, 2017, from http://www.anesi.com/fscale.htm

Ardi, R. (2019). Partisan selective exposure to fake news content. Makara Human Behavior Studies In Asia, 23(1), 6-16. https://doi.org/10.7454/hubs.asia.1160219

Ardi, R. (2021). Media dan perilaku politik (Media and politic behavior). In W. Yustisia, M.A. Hakim, \& R. Ardi (Eds). Psikologi Politik (Political Psychology). Kompas.

Bessi, A. (2016). Personality traits and echo chambers on facebook. Computers in Human Behavior, 65(C), 319-324. https://psycnet.apa.org/doi/10.1016/j.chb.2016.08.016

Beyer, B. K. (1995). Criticial thinking. Phi Delta Kappa Educational Foundation.

Brandt, M. J., Reyna, C., Chambers, J. R., Crawford, J. T., \& Wetherell, G. (2014). The ideological-conflict hypothesis: Intolerance among both liberals and conservatives. Current Directions in Psychological Science, 23(1), 27-34. https://doi.org/10.1177\%2F0963721413510932

Campbell, W. K., Bonacci, A. M., Shelton, J., Exline, J. J., \& Bushman, B. J. (2004). Psychological entitlement: Interpersonal consequences and validation of a self-report measure. Journal of Personality Assesment, 83(1), 29-45. https://doi.org/10.1207/s15327752jpa8301_04

Cappella, J. N., Kim, H. S., \& Albarracin, D. (2015). Selection and transmission processes for information in the emerging media environment: Psychological motives and message characteristics. Media Psychology, 18(3), 396-424. https://doi.org/10.1080/15213269.2014.941112

Clifford, J. S., Boufal, M. M., \& Kurtz, J. E. (2004). Personality traits and critical thinking skills in college students: Empirical tests of a two-factor theory. Assessment, 11(2), 169-176. https://psycnet.apa.org/doi/10.1177/1073191104263250

Crocker, J., \& Luhtanen, R. (1990). Collective self-esteem and ingroup bias. Journal of Personality and Social Psychology, 58(1), 60-67. https://doi.org/10.1037/00223514.58.1.60

Dahlberg, L. (2007). The Internet, deliberative democracy, and power: Radicalizing the public sphere. International Journal of Media and Cultural Politics, 3(1), 47-64. https://doi.org/10.1386/macp.3.1.47_1

Faul, F., Erdfelder, E., Buchner, A., \& Lang, A. G. (2009). Statistical power analyses using G*Power 3.1: Tests for correlation and regression analyses. Behavior Research Method, 41, 1149-1160. https://doi.org/10.3758/BRM.41.4.1149

Fessler, D. M. T., Pisor, A. C., \& Holbrook, C. (2017). Political orientation predicts credulity regarding putative hazards. Psychological Science, 28(5), 651-660. https://doi.org/10.1177\%2F0956797617692108

Flynn, F. J. (2005). Having an open mind: The impact of openness to experience on interracial attitudes and impression formation. Journal of Personality and Social Psychology, 88(5), 816-826. https://doi.org/10.1037/0022-3514.88.5.816 
Gabielkov, M., Ramachandran, A., Chaintreau, A., \& Legout, A. (2016). Social clicks: What and who gets read on Twitter?. SIGMETRICS '16: Proceedings of the ACM SIGMETRICS/International Conference on Measurement and Modeling of Computer Systems. Retrieved July 26, 2017, from https://hal.inria.fr/hal-01281190

Garrett, R. K. (2009). Echo chambers online? Politically motivated selective exposure among Internet news users. Journal of Computer-Mediated, 14(2), 265-285. https://doi.org/10.1111/j.1083-6101.2009.01440.x

Golec de Zavala, A., \& Cichocka, A. (2011). Collective narcissism and anti-Semitism in Poland. Group Processes \& Intergroup Relations, 15(2), 213-229. https://doi.org/10.1177\%2F1368430211420891

Golec de Zavala, A., Dyduch-Hazar, K., \& Lantos, D. (2019). Collective narcissism: Political consequences of investing self-worth in the ingroup's image. Political Psychology, 40(S1), 37-74. https://doi.org/10.1111/pops.12569

Halonen, J. S. (1995). Demystifying critical thinking. Teaching of Psychology, 22(1), 7581. https://doi.org/10.1207/s15328023top2201_23

Hart, W., Albarracin, D., Eagly, A. H., Brechan, I., Lindberg, M. J., \& Merrill, L. (2009). Feeling validated versus being correct: A meta-analysis of selective exposure to information. Psychological Bulletin, 135(4), 555-588. https://doi.org/10.1037/a0015701

Harvey, P., \& Martinko, M. J. (2008). An empirical examination of the role of attributions in psychological entitlement and its outcomes. Journal of Organizational Behaviour, 30(4), 459-476. https://doi.org/10.1002/job.549

Hogg, M., \& Vaughan, G. (2011). Social psychology (6th Edition). Pearson Education Limited.

Jamieson, K. H., \& Cappella, J. N. (2008). Echo chamber: Rush Limbaugh and the conservative media establishment. Oxford University Press.

Kenyon, T., \& Beaulac, G. (2014). Critical thinking education and debiasing. Informal Logic, 34(4), 341-363. https://doi.org/10.22329/i1.v34i4.4203

Kutner, M. (2016). Edward Snowden: Fight "fake news" with truth, not censorship. Newsweek. Retrieved from http://europe.newsweek.com/edward-snowden-jackdorsey-twitter-periscope-531573?rm=eu

Lavine, H., Lodge, M., \& Freitas, K. (2005). Threat, authoritarianism, and selective exposure to information. Political Psychology, 26(2), 219-244. https://doi.org/10.1111/j.14679221.2005.00416.x

Lim, M. (2017). Freedom to hate: Social media, algorithmic enclaves, and the rise of tribal nationalism in Indonesia. Critical Asian Studies, 49(3), 411-427. https://doi.org/10.1080/14672715.2017.1341188

Mastel. (2017). Hasil survey MASTEL tentang wabah hoax nasional (The results of MASTEL survey on national hoax). Retrieved from https://mastel.id/hasil-survey-wabah-hoaxnasional-2017/

Mercier, H., \& Sperber, D. (2011). Why do humans reason? Arguments for an argumentative theory. Behavioral and Brain Sciences, 34(2), 57-74. https://doi.org/10.1017/S0140525X10000968

Mietzner, M. (2015). INDONESIA IN 2014: Jokowi and the repolarization of post-soeharto politics. Southeast Asian Affairs. Retrieved from http://www.jstor.org/stable/44112801

Montag, C. (2019). Filter bubbles: How do filter bubbles affect (political) opinion, taking personality into account? In J. Baldauf, J. Ebner., \& J. Guhl (Eds.). Hate speech and radicalization online (pp. 27-34). The OCCI Research Report London: ISD. 
Nunnally, J. (1978). Psychometric theory. 2nd Edition. McGraw-Hill.

Peacock, C., \& Leavitt, P. (2016). Engaging young people: Deliberative preferences in discussions about news and politics. Social Media + Society, 2(1), 1-11. https://doi.org/10.1177\%2F2056305116637096

Sa, W. C., Stanovich, K. E., \& West, R. F. (1999). The domain specificity and generality of belief bias: Searching for a generalizable critical thinking skill. Journal of Educational Psychology, 91(3), 497-510. https://doi.org/10.1037/0022-0663.91.3.497

Shadrikov, V. D. (2013). The role of reflection and reflexivity in the development of students' abilities. Psychology in Russia: State of the Art, 6(2), 55-64. https://doi.org/10.11621/pir.2013.0205

Shin, J., \& Thorson, K. (2017). Partisan selective sharing: The biased diffusion of factchecking messages on social media. Journal of Communication, 67(2), 233-255. https://doi.org/10.1111/jcom.12284

Snow, J. N., Kern, R. M., \& Curlette, W. L. (2001). Identifying personality traits associated with attrition in systematic training for effective parenting groups. The Family Journal: Counseling and Therapy for Couples and Families, 9(2), 102-108. https://doi.org/10.1177\%2F1066480701092003

Sokolosi, R., Markowitz, E. M., \& Bidwell, D. (2018). Public estimates of support for offshore wind energy: False consensus, pluralistic ignorance, and partisan effects. Energy Policy, 112, 45-55. https://doi.org/10.1016/j.enpol.2017.10.005

Sosu, E. M. (2013). The development and psychometric validation of a critical thinking disposition scale. Thinking Skills and Creativity, 9, 107-119. https://doi.org/10.1016/j.tsc.2012.09.002

Toma, C., Bry, C., \& Butera, F. (2013). Because i'm worth it! (more than others...): Competition, and ownership bias in group decision-making. Social Psychology, 44(4), 248-255. https://doi.org/10.1027/1864-9335/a000109

Tufekci, Z. (2015). Facebook said its algorithms do help form echo chambers, and the tech press missed it. New Perspectives Quarterly, 32(3), 9-12. https://doi.org/10.1111/npqu.11519

Wade, C. (1995). Using writing to develop and assess critical thinking. Teaching of Psychology, 22(1), 24-28. https://doi.org/10.1207\%2Fs15328023top2201_8

Wason, P. (1960). On the failure to eliminate hypotheses in a conceptual task. Quarterly Journal of Experimental Psychology, 12, 129-1. https://doi.org/10.1080/17470216008416717

Watson, G., \& Glaser, E. M. (1991). Watson-Glaser Critical Thinking Appraisal Manual. Psychological Corporation.

Zuckerman, M. (1979). Attribution of success and failure revisited, or the motivational bias is alive and well in attribution theory. Journal of Personality, 47(2), 245-287. https://doi.org/10.1111/j.1467-6494.1979.tb00202.x 